\title{
Impact of dietary protein intake and obesity on lean mass in middle-aged individuals after a 12-year follow-up: the Korean Genome and Epidemiology Study (KoGES)
}

\author{
Eunjin $\mathrm{So}^{1,2}$, Seul Ki Choi ${ }^{3 *}$ and Hyojee Joung ${ }^{2 *}$ \\ ${ }^{1}$ Department of Clinical Nutrition, The Catholic University of Korea Seoul St, Mary's Hospital, Seoul, Republic of Korea \\ ${ }^{2}$ Department of Public Health, Graduate School of Public Health E Institute of Health and Environment, Seoul National \\ University, Gwanak-gu, Seoul 08826, Republic of Korea \\ ${ }^{3}$ Department of Health Promotion, Education, and Behavior, Arnold School of Public Health, University of South Carolina, 915 \\ Greene Street, Columbia, SC 29208, USA
}

(Submitted 8 November 2018 - Final revision received 9 April 2019 - Accepted 27 April 2019; First published online 10 June 2019)

\begin{abstract}
The present study investigated the association between protein intake and lean mass according to obesity status over a 12-year period. Data on 4412 participants aged 40-69 years were obtained from the Korean Genome and Epidemiology Study. The usual dietary protein intake of these participants was assessed at baseline using a semi-quantitative FFQ. Body composition was measured using bioelectrical impedance analysis at baseline and after a 12-year follow-up. Linear mixed-effects models were used to examine the associations between lean mass after a 12-year follow-up and protein intake at baseline. After adjusting for covariates and lean mass at baseline, comparisons between the highest and lowest tertiles revealed that dietary protein intake was positively associated with lean mass in both men $(\beta=0 \cdot 79, P=0 \cdot 001)$ and women $(\beta=0 \cdot 28$, $P=0.082)$ after the 12-year period; however, those differences were attenuated after additional adjustment for fat mass at baseline and were stronger in the normal-weight group (men, $\beta=0.85, P=0.002$; women, $\beta=0.97, P<0.001$ ) but were not detected in the obese group. In the obese group, age (men, $\beta=4.08, P<0.001$; women, $\beta=2 \cdot 61, P<0 \cdot 001$ ) and regular physical activity (men, $\beta=0 \cdot 88, P=0 \cdot 054$; women, $\beta=0 \cdot 76$, $P<0.001$ ) were significantly associated with lean mass after 12 years of follow-up. The results of the present study showed that protein intake may contribute to the prevention of ageing-related lean mass loss; however, the impact of this intake may vary depending on obesity status. Therefore, the maintenance of a healthy body weight during ageing through enhanced protein intake is likely to confer health benefits.
\end{abstract}

Key words: Protein intake: Lean mass: Obesity: Korean Genome and Epidemiology Study (KoGES): Cohort studies

The number of individuals over 60 years of age worldwide is expected to increase from 900 million to 2 billion between 2015 and $2050^{(1)}$, with a subsequent increase in the number of people at risk of deteriorating strength and mobility related to muscle loss. Recent estimates indicate that the prevalence of sarcopenia is $5-13 \%$ in individuals $60-70$ years of age and $11-50 \%$ in those $\geq 80$ years of age ${ }^{(2)}$. Sarcopenia is a syndrome characterised by a progressive and generalised loss of skeletal muscle mass and strength and is associated with an increased risk of falls and fractures, reduced cardiopulmonary function, metabolic syndrome and insulin resistance; accordingly, this condition eventually results in disability, hospitalisation and death among older individuals ${ }^{(3)}$. Although there are few estimates of the financial burden of sarcopenia in older adults, the healthcare costs of this condition are likely to be high ${ }^{(4)}$.
One prospective study estimated that sarcopenia would increase hospitalisation costs by 58.5 and $34 \%$ for patients $<65$ and $\geq 65$ years of age, respectively ${ }^{(5)}$.

Ageing is probably the most important factor contributing to the loss of muscle mass, although this decline can also be accelerated by modifiable lifestyle factors such as physical inactivity, smoking, alcohol consumption and undernutrition ${ }^{(6)}$. While protein intake has been the main nutritional focus ${ }^{(7,8)}$, many older adults do not consume adequate amounts of dietary protein due to reduced energy needs, increased physical dependency, anorexia, changes in food preference, anabolic resistance and increased inflammatory and catabolic conditions ${ }^{(9,10)}$.

Additionally, obesity has become an epidemic in the elderly ${ }^{(11)}$, and obese older adults face high risks of age-related muscle wasting, such as sarcopenia ${ }^{(12,13)}$. In older adults with

Abbreviations: \%BF, percentage body fat; BIA, bioelectrical impedance analysis.

* Corresponding authors: Seul Ki Choi, email choi27@mailbox.sc.edu; Hyojee Joung, email hjjoung@snu.ac.kr 
sarcopenic obesity, sarcopenia and obesity may synergistically increase their effects on physical disability, metabolic disorders, CVD and mortality ${ }^{(12,14-16)}$. Although the molecular mechanisms that underlie obesity-associated dysfunctions in lipid and glucose metabolism have been studied extensively ${ }^{(17)}$, the effects of obesity on the processes that regulate muscle protein metabolism are poorly understood ${ }^{(18)}$. Intramuscular lipids act as chemoattractants for macrophages that produce proinflammatory cytokines $^{(19)}$. These cytokines not only directly contribute to the breakdown of muscle proteins ${ }^{(20)}$ but also interfere with the accretion of contractile material caused by chronic low-intensity muscle overloading ${ }^{(21)}$. Previously, Erskine et al. described the paradox that circulating proinflammatory cytokines play different roles in neuromuscular remodelling according to the age and adiposity of the individual ${ }^{(22)}$.

According to the Korea National Statistical Office, the percentage of Korean population aged $\geq 65$ years is expected to rise to $24.5 \%$ by 2030 and to $38.1 \%$ by $2050^{(23)}$. Along with a rapid growth in the number of elderly individuals in Korea, sarcopenia and sarcopenic obesity have become important issues in this country. In the Korean Sarcopenic Obesity Study that included 526 healthy volunteers 20-88 years of age, the prevalence of sarcopenic obesity in older ( $\geq 60$ years) men and women was $5 \cdot 1$ and $12.5 \%$, respectively, as of 2008 . However, there have been no Korean cohort studies on the long-term effects of dietary protein on changes in muscle mass according to obesity status.

In the elderly, the maintenance of muscle mass and strength is critical to the abilities of an individual to survive multiple co-morbidities and meet their physical demands. Therefore, we conducted a prospective cohort study of elderly Korean subjects to investigate the effects of protein intake on changes in lean mass according to obesity status.

\section{Materials and methods}

\section{Data source and study population}

Data were obtained from a large community-based cohort of the Korean Genome and Epidemiology Study (KoGES). The eligibility criteria for the participants of the KoGES at baseline included residents between the ages of 40 and 69 years who had lived in Ansan (urban) or Ansung (rural), Korea, for at least 6 months before enrolment. Baseline examinations were performed in 2001 and 2002, and follow-up examinations continued every 2 years until the end of 2014. Detailed information about the present study has been provided elsewhere ${ }^{(24)}$. Of the original 10030 participants, 4412 were included in the final analysis after excluding those who did not complete the baseline FFQ or anthropometric data ( $n$ 2417), who had abnormally low or high daily energy intakes $(<500$ or $>5000 \mathrm{kcal} / \mathrm{d}(<2092$ or $>20920$ $\mathrm{kJ} / \mathrm{d}), n 56$ ), who did not participate in follow-up examinations ( $n$ 3042), or who had low skeletal muscle mass $(<35.71 \%$ in men, $<30 \cdot 70 \%$ in women $)^{(25)}$ at baseline ( $n$ 103). All participants signed the written informed consent form. The present study was approved by the Institutional Review Board (no. KC17ZESI0645) of the Catholic Medical Center.

\section{Assessment of usual dietary protein intake}

At baseline, the participants' usual dietary protein intake was assessed by trained dietitians using a validated 103-item semiquantitative $\mathrm{FFQ}^{(26)}$. There were nine response options for the frequency of each food (never or almost never, once per month, two or three times per month, one or two times per week, two or three times per week, three or four times per week, five or six times per week, once daily, twice daily, or three times daily) and three response options for the portion size of each food ( $1 / 2$ serving, 1 serving and $\geq 2$ servings). To enhance the accuracy of recall of serving size, pictures of each food item were used as a reference. The daily intakes of protein and other nutrients by each individual were estimated from the sum of the intakes of each food item, based on the Food Composition Database (Seoul, Korea: The Rural Development Administration, 2007). Among the 103 food items listed on the FFQ, seventy-nine items classified as the main food sources contributing to protein intake (nine food items from meats including beef, pork, poultry and meat products, fifteen food items from fish and shellfish, three food items from soyabeans, four food items from milk, one food item from eggs, seven food items from rice and other cereals, twenty-seven food items from vegetables, ten food items from noodles and breads and three food items from potatoes) were assessed to calculate each subject's protein intake.

\section{Anthropometric measurements}

Fat mass and lean mass (fat-free mass) were assessed using multi-frequency bioelectrical impedance analysis (MF-BIA; InBody 3.0; Biospace) according to standard procedures. The MF-BIA technique assumes that the human body comprises five interconnecting cylinders and measures direct impedance in these body compartments. Using an eight-polar tactile electrode system, impedance was measured at four specific frequencies (550 250 and $500 \mathrm{kHz}$ ) in five segments (right arm, left arm, trunk, right leg and left leg) for the estimation of total body water (TBW). The lean mass was estimated from the TBW and anthropometric measurements, using an algorithm for the Asian population. The fat mass was estimated by subtracting the lean mass from the total body weight. The participants fasted overnight prior to BIA assessment. Before the examination, the researchers confirmed whether the participant had experienced intensive exercise, bathing or excessive sweating. BMI was calculated as the weight (kg) divided by the height $(\mathrm{m})$ squared. Although there is no standardised definition of obesity according to fat mass, the participants were categorised into two groups by percentage body fat (\%BF) with reference to Asian epidemiological studies (normal group: \%BF $<25$ for men and $<30$ for women; obese group: $\% \mathrm{BF} \geq 25$ for men and $\geq 30$ for women $)^{(27,28)}$.

\section{Covariates}

All lifestyle-related information was gathered with an interviewer-administered questionnaire. The questionnaire included questions on sex, age, marital status, education, income, smoking, alcohol consumption, regular physical activity and selfperceived dental health status. Smoking status was used to classify participants into 'smokers' (current smokers) and 
'non-smokers' (former smokers and non-smokers). Alcohol consumption was used to classify participants into 'alcohol drinkers' (current drinkers) and 'non-drinkers' (former and never drinkers). Regular physical activity was defined as 'yes' if the participant performed $>2.5 \mathrm{~h}$ of exercise per week according to the WHO recommendation ${ }^{(29,30)}$. The self-perceived dental health status was categorised as poor or others (good and fair). Chronic diseases were measured by participants' self-report of the presence or absence of ten chronic conditions (myocardial infarction, congestive heart failure, coronary artery disease, peripheral arterial disease, cerebrovascular disease, asthma, chronic obstructive pulmonary disease, cancer, dementia and arthritis).

\section{Statistical analysis}

Because of well-established sex differences in age-related changes in lean mass and muscle strength ${ }^{(31)}$, all analyses were performed separately for men and women. Protein intake was examined by the protein density method, in which nutrient intake was divided by total energy intake (in $\mathrm{g}$ per $1000 \mathrm{kcal}$ $(4184 \mathrm{~kJ}))^{(32)}$. The protein intake per $1000 \mathrm{kcal}(4184 \mathrm{~kJ})$ at baseline was categorised into tertiles. The baseline characteristics of study participants were compared with respect to the tertiles of protein intake per $1000 \mathrm{kcal}(4184 \mathrm{~kJ})$, using Mantel-Haenszel $\chi^{2}$ tests for categorical variables and linear regression analyses for continuous variables. A one-way ANOVA was used to test for between-group differences in percentage change in body composition after a 12-year follow-up, using the lowest tertile as the reference group. Independent Student's $t$ test was used to examine the differences between older ( $\geq 50$ years) and younger participants $(<50$ years) in terms of percentage change in body composition after a 12-year follow-up. Multiple linear regression analyses were performed to determine the relative contributions of evaluated characteristics to the lean mass at baseline. Fat mass (kg), age $(<60 / \geq 60$ years), protein intake (tertile $1 /$ tertile $2 /$ tertile 3 ; T1/T2/T3), marital status (married/ others), education ( $\geq$ college/others), income ( $\geq 3000000 \mathrm{KRW}$ (Korean won) per month/others), smoking (yes/no), alcohol consumption (yes/no), regular physical activity (yes/no), selfperceived dental health status (poor/others) and chronic disease (yes/no) were included as covariates in the model. Variables with $P$ values $<0.05$ were selected during stepwise regression procedures. The subjects were categorised into normal and obese groups for linear mixed-effects models to examine the independent effect of protein intake on lean mass after 12 years of follow-up. Potential confounding variables were selected using stepwise regression procedures and entered into the models. Model 1 was adjusted for age, income, alcohol consumption, smoking, regular physical activity and chronic disease, and model 2 was adjusted for the variables in model 1 plus fat mass. IBM SPSS Statistics for Windows, version 24.0 (IBM, Corp.), was used for all statistical analyses. A two-sided $P$ value $<0.05$ was considered statistically significant.

\section{Results}

Table 1 shows the characteristics of study participants according to protein intake at baseline. The protein intakes ( $\mathrm{g} / \mathrm{kg}$ body weight) by tertiles 1,2 and 3 were $0 \cdot 8,1 \cdot 0$, and $1.3 \mathrm{~g}$ in men and $0 \cdot 9,1 \cdot 1$ and $1.4 \mathrm{~g}$ in women, respectively. Both men and women with high protein intakes were significantly younger $(P<0.001)$, were more likely to live in a city $(P<0.001)$, had a higher educational level $(P<0.001)$, earned a higher income $(P<0.001)$, were married ( $P=0.019$ for men, $<0.001$ for women), consumed alcohol currently ( $P<0.001$ for men, 0.001 for women), and were physically active $(P<0 \cdot 001)$. Smoking status was not significantly associated with protein intake. Additionally, men and women with higher protein intakes had higher intakes of energy $(P<0 \cdot 001)$ and energy from fat $(P<0.001)$ and a lower intake of energy from carbohydrates $(P<0 \cdot 001)$. Regarding body composition, men with a high protein intake had higher weight $(P<0 \cdot 001)$, BMI $(P<0 \cdot 001)$, fat mass $(P<0.001), \% \mathrm{BF}(P<0.001)$ and lean mass $(P<0.001)$ at baseline, whereas among women, only lean mass differed significantly in relation to protein intake $(P=0.005)$.

In men and women with the highest protein intakes, dietary protein was mostly derived from meats $(22.9 \%$ in men and $18.4 \%$ in women), while dietary protein was mostly derived from vegetable proteins with rice and other cereals in men and women with the lowest protein intakes $(41.8 \%$ in men and $44.1 \%$ in women) (Fig. 1).

Among men, the percentage change in body composition after 12 years of follow-up did not differ significantly according to protein intake, whereas women with a higher protein intake had lower reductions in weight, BMI and lean mass during the follow-up period ( $P<0.001, P=0.014$ and $P<0.001$, respectively). Among both men and women, older participants ( $\geq 50$ years) had a greater reduction in lean mass compared with the younger group ( $<50$ years) $(P<0 \cdot 001 ;$ T1, T2 and T3) (Fig. 2$)$.

Table 2 shows the results of multiple linear regression models using a stepwise procedure for selecting variables that predicted lean mass at baseline. In men, a higher fat mass $(\beta=0.59$, $P<0.001)$, younger age $(\beta=3.75, P<0.001)$, regular physical activity $(\beta=1.07, \quad P<0.001)$, higher income $(\beta=0.83$, $P=0.002)$, current smoking $(\beta=0.72, P=0.002)$, protein intake $(\beta=0.50, P=0.039)$ and the presence of chronic disease $(\beta=-2 \cdot 25, P=0 \cdot 019)$ were associated with a higher lean mass at baseline. In women, a higher fat mass $(\beta=0.46, P<0.001)$, younger age $(\beta=2.20, P<0.001)$, regular physical activity $(\beta=0.89, P<0.001)$ and alcohol consumption $(\beta=0.63$, $P<0.001)$ were associated with a higher lean mass at baseline.

In linear mixed-effects models, a higher protein intake at baseline was associated with a higher lean mass after 12 years of follow-up in both men $(\beta=0.79, P=0.001$; highest $v$. lowest tertile) and women $(\beta=0 \cdot 28, P=0 \cdot 082$; highest $v$. lowest tertile) after adjusting for covariates (Table 3 ). These associations were attenuated after additional adjustment for fat mass at baseline. In further evaluation according to obesity status, the associations were stronger in the normal-weight group (men, $\beta=0.85$, $P=0.002$; highest $v$. lowest tertile; women, $\beta=0.97$, $P<0.001$; highest $v$. lowest tertile) but were not detected in the obese group. Age (men, $\beta=4.08, P<0.001$; women, $\beta=2.61, P<0.001$ ) and regular physical activity (men, $\beta=0.88, P=0.054$; women, $\beta=0.76, P<0.001$ ) were significantly associated with lean mass after 12 years of follow-up, regardless of obesity status. Higher income (men, $\beta=1 \cdot 36$, $P=0.001$; women, $\beta=0.43, P=0 \cdot 046$ ) and alcohol consumption 
Table 1. Characteristics of study participants by levels of protein intake

(Mean values and standard deviations; percentages)

\begin{tabular}{|c|c|c|c|c|c|c|c|c|c|c|c|c|c|c|}
\hline \multirow{3}{*}{ Protein intake (tertiles)... } & \multicolumn{7}{|c|}{ Men ( $n$ 2096) } & \multicolumn{7}{|c|}{ Women ( $n$ 2316) } \\
\hline & \multicolumn{2}{|c|}{$\mathrm{T} 1^{*}$} & \multicolumn{2}{|c|}{ T2 } & \multicolumn{2}{|c|}{ T3 } & \multirow{2}{*}{$\begin{array}{l}P_{\text {for trend }} \dagger \\
\quad \text { or } P\end{array}$} & \multicolumn{2}{|c|}{ T1 } & \multicolumn{2}{|c|}{ T2 } & \multicolumn{2}{|c|}{ T3 } & \multirow{2}{*}{$\begin{array}{l}P_{\text {for trend }} \\
\quad \text { or } P\end{array}$} \\
\hline & Mean & SD & Mean & SD & Mean & SD & & Mean & SD & Mean & SD & Mean & SD & \\
\hline \multicolumn{15}{|c|}{ Demographics and lifestyles at baseline } \\
\hline Age (years) & $51 \cdot 8$ & 8.5 & $49 \cdot 6$ & $7 \cdot 6$ & $49 \cdot 3$ & $7 \cdot 6$ & $<0.001$ & 53.33 & 9.0 & 50.5 & 8.1 & $48 \cdot 7$ & 7.4 & $<0.001$ \\
\hline Residential area (city, \%) & \multicolumn{2}{|c|}{$48 \cdot 1$} & \multicolumn{2}{|c|}{$75 \cdot 2$} & \multicolumn{2}{|c|}{78.0} & $<0.001$ & \multicolumn{2}{|c|}{$40 \cdot 9$} & \multicolumn{2}{|c|}{67.9} & \multicolumn{2}{|c|}{74.9} & $<0.001$ \\
\hline Education ( $\geq$ college, \%) & \multicolumn{2}{|c|}{$16 \cdot 6$} & \multicolumn{2}{|c|}{$26 \cdot 9$} & \multicolumn{2}{|c|}{31.4} & $<0.001$ & \multicolumn{2}{|c|}{$4 \cdot 1$} & \multicolumn{2}{|c|}{$8 \cdot 7$} & \multicolumn{2}{|c|}{11.6} & $<0.001$ \\
\hline $\begin{array}{l}\text { Household income } \\
\text { ( } \geq 3000000 \mathrm{KRW}, \%)\end{array}$ & \multicolumn{2}{|c|}{$15 \cdot 7$} & \multicolumn{2}{|c|}{$28 \cdot 1$} & \multicolumn{2}{|c|}{$36 \cdot 6$} & $<0.001$ & $8 \cdot($ & & $18 \cdot \varsigma$ & & 24 . & & $<0.001$ \\
\hline Marital status (married, \%) & 95. & & 97. & & 98. & & 0.019 & 83.7 & & $89 \cdot 6$ & & 91 . & & $<0.001$ \\
\hline Smoking (yes, \%) & 46. & & 42. & & 45. & & 0.623 & 1. & & $2 \cdot 3$ & & 2. & 8 & 0.245 \\
\hline Chronic diseases (yes, \%) & 1 . & 9 & 1 . & 1 & 1 . & 3 & 0.381 & 6. & & 4.7 & & 2 . & 5 & $<0.001$ \\
\hline Multi-morbidity $(n)$ & 0.1 & 0.2 & 0.0 & 0.2 & 0.0 & 0.2 & 0.181 & 0.1 & 0.3 & 0.1 & 0.3 & 0.1 & 0.2 & $<0.001$ \\
\hline $\begin{array}{l}\text { Dental health status } \\
\text { (poor, \%) }\end{array}$ & 39 . & & 40 . & & 36 . & & 0.144 & $47 \cdot$ & & 41.5 & & 35 . & & $<0.001$ \\
\hline Alcohol drinking (yes, \%) & 66 . & & 73 & & 80 . & & $<0.001$ & 22 & & $27 \cdot 7$ & & 29 . & & 0.001 \\
\hline $\begin{array}{l}\text { Regular physical activity } \\
\text { (yes, \%) }\end{array}$ & 11 . & & 18 . & & 23 & & $<0.001$ & 9 & & 18 & & 25 . & & $<0.001$ \\
\hline Nutrient intake at baseline & & & & & & & & & & & & & & \\
\hline Energy $(\mathrm{kcal} / \mathrm{d}) \ddagger$ & $1904 \cdot 3$ & 608.5 & $1969 \cdot 7$ & 483.8 & $2138 \cdot 3$ & $560 \cdot 1$ & $<0.001$ & 1779.2 & 606.9 & 1890.5 & $546 \cdot 4$ & $1970 \cdot 6$ & $632 \cdot 3$ & $<0.001$ \\
\hline $\begin{array}{l}\text { Carbohydrate } \\
\text { (\% of energy) }\end{array}$ & $75 \cdot 4$ & 3.9 & $69 \cdot 9$ & 3.5 & $63 \cdot 7$ & $5 \cdot 2$ & $<0.001$ & $77 \cdot 5$ & $4 \cdot 0$ & $71 \cdot 8$ & $3 \cdot 7$ & $65 \cdot 2$ & $5 \cdot 0$ & $<0.001$ \\
\hline Fat (\% of energy) & 11.8 & 3.7 & $15 \cdot 5$ & 3.5 & $19 \cdot 3$ & 4.3 & $<0.001$ & 9.9 & 3.6 & $13 \cdot 9$ & 3.6 & $18 \cdot 2$ & 4.3 & $<0.001$ \\
\hline Protein (\% of energy) & $11 \cdot 3$ & 0.9 & 13.5 & 0.5 & $16 \cdot 0$ & 1.6 & $<0.001$ & 11.2 & 1.0 & $13 \cdot 4$ & 0.5 & $15 \cdot 9$ & 1.5 & $<0.001$ \\
\hline Protein $(\mathrm{g} / \mathrm{d})$ & $54 \cdot 1$ & $17 \cdot 7$ & $66 \cdot 3$ & $16 \cdot 9$ & 85.8 & $25 \cdot 2$ & $<0.001$ & $50 \cdot 0$ & $17 \cdot 7$ & $63 \cdot 3$ & 18.5 & $78 \cdot 6$ & $27 \cdot 8$ & $<0.001$ \\
\hline Protein ( $\mathrm{g} / \mathrm{kg}$ body weight) & 0.8 & 0.3 & 1.0 & 0.3 & 1.3 & 0.4 & $<0.001$ & 0.9 & 0.3 & 1.1 & 0.4 & 1.4 & 0.5 & $<0.001$ \\
\hline Fat (\% of energy) & $11 \cdot 8$ & 3.7 & $15 \cdot 5$ & 3.5 & $19 \cdot 3$ & $4 \cdot 3$ & $<0.001$ & 9.9 & 3.6 & $13 \cdot 9$ & 3.6 & $18 \cdot 2$ & 4.3 & $<0.001$ \\
\hline sition at baseline & & & & & & & & & & & & & & \\
\hline Weight (kg) & $66 \cdot 9$ & 9.4 & $68 \cdot 2$ & 9.0 & $69 \cdot 8$ & $9 \cdot 2$ & $<0.001$ & $58 \cdot 3$ & $8 \cdot 3$ & $59 \cdot 1$ & 7.5 & 58.9 & $7 \cdot 4$ & 0.111 \\
\hline BMI $\left(\mathrm{kg} / \mathrm{m}^{2}\right)$ & $24 \cdot 1$ & $2 \cdot 8$ & $24 \cdot 3$ & $2 \cdot 7$ & $24 \cdot 7$ & $2 \cdot 7$ & $<0.001$ & $24 \cdot 7$ & $3 \cdot 1$ & 24.7 & 2.8 & $24 \cdot 4$ & $2 \cdot 8$ & 0.078 \\
\hline Fat mass $(\mathrm{kg})$ & 14.4 & 4.5 & 14.9 & 4.5 & $15 \cdot 6$ & 4.5 & $<0.001$ & 18.5 & 4.9 & $18 \cdot 8$ & 4.5 & 18.5 & 4.5 & 0.410 \\
\hline Body fat (\%) & $21 \cdot 1$ & 4.8 & 21.5 & 4.8 & $22 \cdot 0$ & 4.5 & $<0.001$ & $31 \cdot 3$ & $5 \cdot 0$ & 31.5 & 4.6 & $31 \cdot 0$ & 4.8 & 0.179 \\
\hline Lean mass $(\mathrm{kg})$ & 52.5 & $6 \cdot 3$ & 53.2 & $6 \cdot 0$ & $54 \cdot 3$ & $6 \cdot 1$ & $<0.001$ & $39 \cdot 8$ & 4.5 & $40 \cdot 3$ & 4.1 & 40.5 & 4.2 & 0.005 \\
\hline
\end{tabular}

KRW, Korean won.

* Tertiles of protein intake per $1000 \mathrm{kcal}(4184 \mathrm{~kJ})$ at baseline.

$\dagger P_{\text {for trend }}$ was calculated from linear regression analysis for continuous variables and Mantel-Haenszel $\chi^{2}$ for categorical variables.

† To convert kcal to kJ, multiply by $4 \cdot 184$.

(men, $\beta=1 \cdot 16, P=0.005$; women, $\beta=0.56, P=0.002$ ) in both obese men and women, and smoking $(\beta=1.82, P<0.001)$ and chronic disease $(\beta=-2.42, P=0.071)$ in obese men, were significantly associated with lean mass after 12 years of follow-up.

\section{Discussion}

To our knowledge, this is the first large, community-based prospective cohort study in Korea to investigate the associations between protein intake and changes in lean mass according to obesity status in middle-aged individuals. The results showed that men and women with higher protein intakes had a higher lean mass after 12 years of follow-up, but that these differences were attenuated after additional adjustment for fat mass at baseline. The associations were stronger in the normal-weight group but were not detected in the obese group.

Women with a higher protein intake had lower reductions in lean mass during the follow-up period. In a meta-analysis of adult men and women with a mean age of $\geq 50$ years, a higher protein intake ( $\geq 25 \%$ of the daily total energy intake or $\geq 1 \cdot 0$ $\mathrm{g} / \mathrm{kg}$ per d) was associated with increased lean mass retention and fat mass loss during intentional weight $\operatorname{loss}^{(33)}$. Another cohort study investigated the association between dietary protein and changes in lean mass and appendicular lean mass in older, community-dwelling men and women, and reported that community-dwelling older adults with the highest quintile of protein intake lost approximately $40 \%$ less total lean body mass and appendicular lean mass over 3 years compared with the loss in the group with the lowest quintile of protein intake ${ }^{(34)}$. Our study showed similar results in women, not in men. In women, a high protein intake was associated with smaller reductions in lean mass, weight and BMI. However, there was no significant association in men between protein intake and changes in body composition. The Quebec longitudinal study on Nutrition as a Determinant of Successful Aging reported a stronger association between protein distribution (standard deviation of $g$ of protein per meal divided by $g$ of total protein) and muscle strength in women than in men (men, $\beta=-0.44, P<0.05$; women, $\beta=-0.68, P<0.001)^{(35)}$. Other studies showed that the associations between diet and grip strength (men, $\beta=0 \cdot 18, P=0 \cdot 035$; women, $\beta=0.27, \quad P<0.001)^{(36)}$ or physical performance (men, $\beta=0.995, P=0.383$; women, $\beta=0.985, P=0.091)^{(37)}$ 

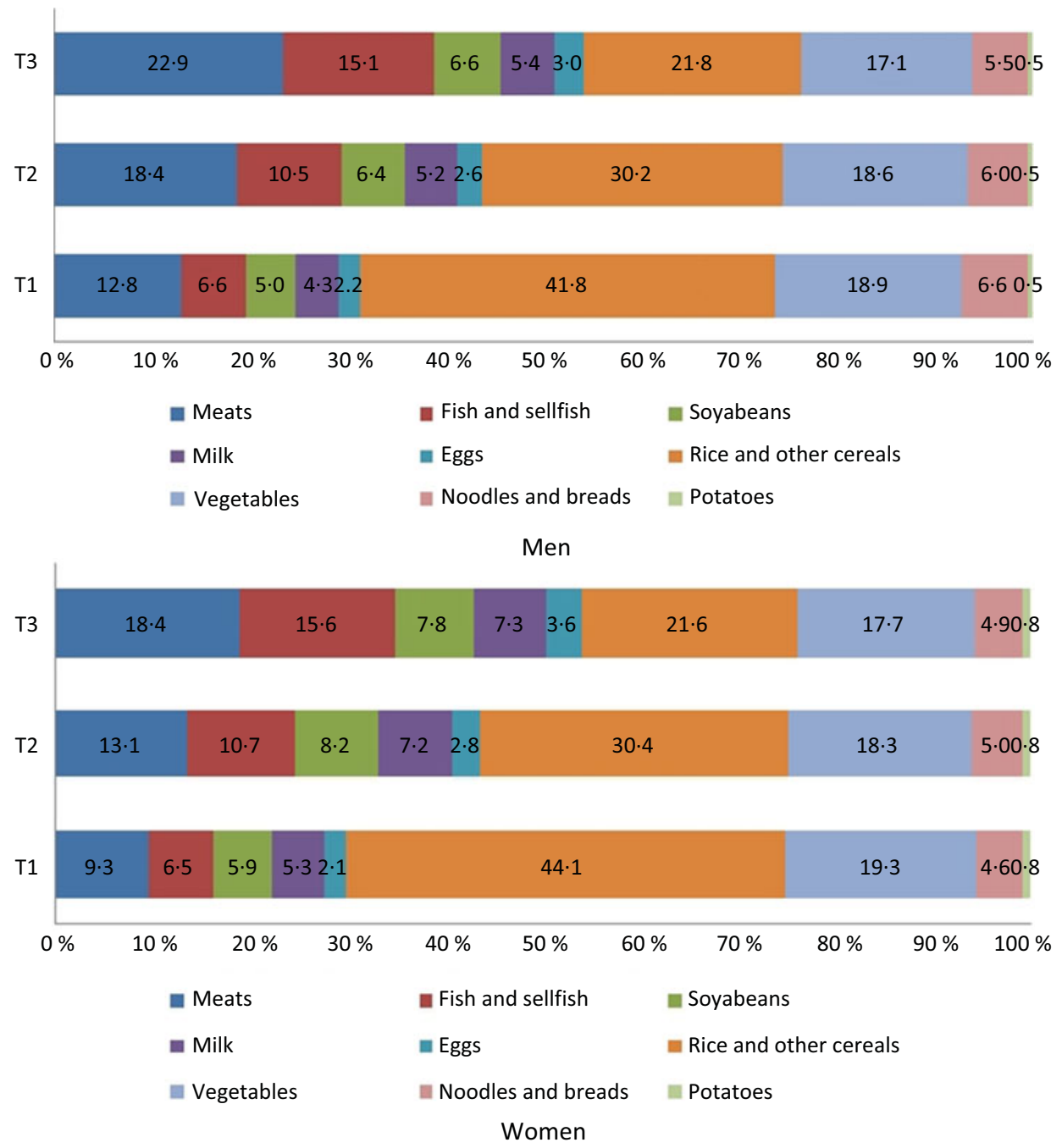

Fig. 1. Contribution of protein source foods to total daily protein intake.

were stronger in women than in men. Although those studies did not focus on protein intake, the authors noted that women usually had healthier diets with higher micronutrient densities compared with men, which may have affected women's health outcomes such as grip strength or physical performance. In another study, however, total protein intake was related to lean mass only in men, while the protein distribution was related to lean mass in both sexes but more so in men ${ }^{(38)}$. Declining muscle mass can be affected by lifestyle factors as well as age-related physiological and systemic changes in the body ${ }^{(7)}$; therefore, the roles played by various lifestyle factors in age-related changes in body function should be further investigated to clarify sex-specific associations between dietary protein intake and lean mass.

Consistent with the results of previous studies, we observed a positive association between protein intake and lean mass retention, after adjusting for covariates and lean mass at baseline in both men and women. Previous cohort studies of older adults have demonstrated that the quantity of dietary protein intake is the main nutritional factor associated with preserving muscle mass and maintaining physical function ${ }^{(39-41)}$. In one of these studies, compared with women in the lowest tertile of protein intake $(<66 \mathrm{~g} / \mathrm{d})$, those in the highest tertile $(>87 \mathrm{~g} / \mathrm{d})$ had $5 \cdot 4-6 \cdot 0 \%$ higher whole-body and appendicular lean mass ${ }^{(40)}$. A Japanese study also reported that the consumption of seafood, dairy products and protein-rich foods may help older adults to maintain their independence ${ }^{(42)}$. There is growing evidence that protein intake levels exceeding the recommended daily allowance may benefit elderly adults by preventing or mitigating sarcopenia $^{(9,43)}$. A review study also concluded that a protein intake level meeting the nutritional requirements of all healthy individuals does not provide protection from age-related sarcopenia $^{(44-46)}$. According to data from the 2008-2012 Korean National Health and Nutrition Examination Survey, $18.8 \%$ of adults $\geq 60$ years and $34.9 \%$ of adults $\geq 70$ years consumed less protein than the estimated average requirements for Koreans ( $40 \mathrm{~g} / \mathrm{d}$ for men and $35 \mathrm{~g} / \mathrm{d}$ for women), indicating that many older Korean adults may have insufficient protein intake ${ }^{(47)}$. Therefore, the effects of dietary protein intake in the attenuation of age-related loss of lean mass among older adults require further investigation.

The results of the present study showed that obesity reduced the muscle preservation effects of dietary protein. Dietary 
(a)

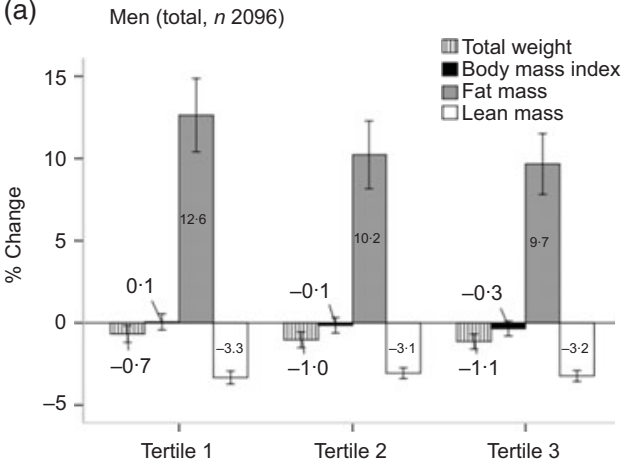

(c)

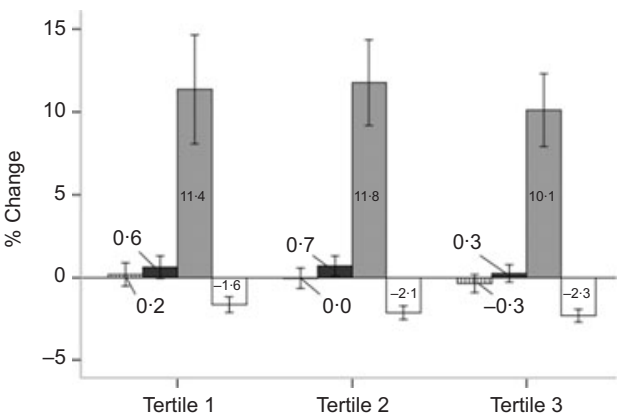

(e)

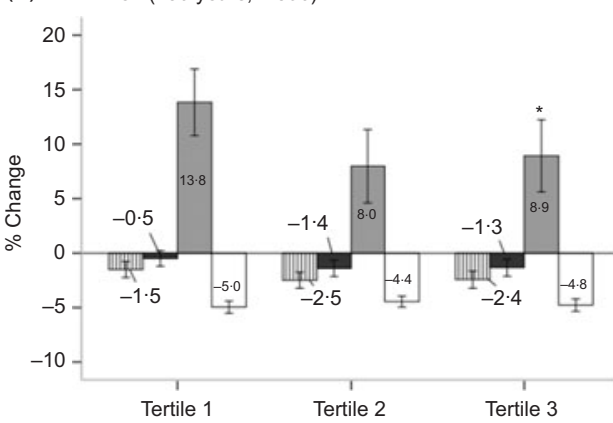

(b)

Women (total, $n$ 2316)

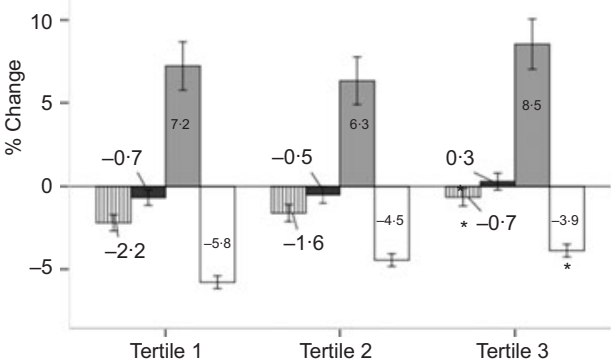

(d)

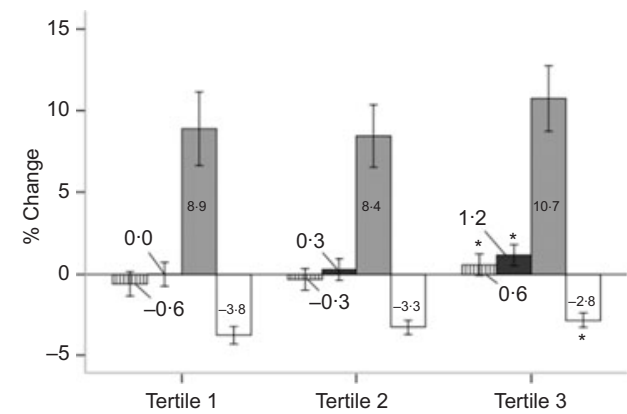

(f)

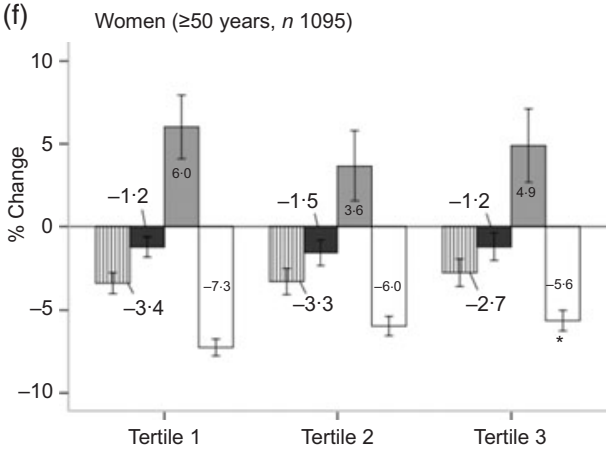

Fig. 2. Percentage change in body composition over 12 years by tertiles of protein intake per $1000 \mathrm{kcal}(4184 \mathrm{~kJ})$. Percentage change $=((12-\mathrm{year}$ follow-up value baseline value)/baseline value $\times 100)$. Values are means. ${ }^{*}$ Significantly linear trend across tertiles of protein intakes: $P_{\text {for trend }}<0.05$. Among both men and women, older participants ( $\geq 50$ years) had a greater reduction in lean mass, compared with the younger group ( $<50$ years) $(P<0.001 ; \mathrm{T} 1, \mathrm{~T} 2$ and T3) using Student's $t$ test.

protein intake had a significant effect on lean mass after the 12year follow-up in the normal-weight group but not in the obesity group. Sarcopenia and obesity share several pathophysiological mechanisms $^{(12)}$ that may synergistically increase the risk of negative health outcomes ${ }^{(48)}$. Moreover, the rates of physical disabilities $^{(15,49)}$, co-morbidities ${ }^{(50)}$ and mortality ${ }^{(51,52)}$ are higher in sarcopenic obesity than in sarcopenia or obesity alone. A recent cross-sectional study reported that normal-weight women had 14 and $10 \%$ higher muscle quality values (i.e. leg power (W) normalised for lower-body mineral-free lean mass (kg)) compared with overweight and obese women, respectively ${ }^{(53)}$. Furthermore, fat mass was associated with functional decline and muscle weakness in elderly individuals $^{(39,54,55)}$. In contrast, a recent meta-analysis showed that protein supplementation combined with resistance exercise training effectively prevented age-related muscle mass attenuation and leg strength loss in the elderly, regardless of body weight ${ }^{(56)}$. However, on the basis of protein supplementation alone, individuals with a mean BMI $\geq 30 \mathrm{~kg} / \mathrm{m}^{2}$ did not exhibit a greater change in muscle volume and handgrip strength compared with those with a mean BMI $<30 \mathrm{~kg} / \mathrm{m}^{2}$. The authors concluded that protein supplementation may not prevent age-related muscle loss in obese elderly. Although little is known about the mechanisms underlying the impact of obesity on lean mass in the elderly, obesity may be accompanied by a state of chronic oxidative stress, which could promote protein breakdown and direct muscle fibres into a catabolic state that ultimately leads to muscle wasting ${ }^{(57)}$. Moreover, in overweight elderly, ineffective autophagic mechanisms may be associated with insulin resistance due to the inhibition of protein synthesis and accumulation of misfolded proteins, thus contributing to age-related skeletal muscle loss ${ }^{(58)}$. In our study, protein intake may have had less impact on the prevention of lean mass loss in elderly obese than in elderly adults with normal weight. Further research is needed to fully understand the impact of obesity on lean mass. 
Table 2. Predictors of lean mass at baseline

( $\beta$-Coefficients with their standard errors; $R^{2}$ )

\begin{tabular}{|c|c|c|c|c|c|c|c|c|c|c|}
\hline \multirow[b]{2}{*}{ Predictor† } & \multicolumn{5}{|c|}{ Men (n 2096) } & \multicolumn{5}{|c|}{ Women ( $n$ 2316) } \\
\hline & $\beta$ & SE & $P$ & $R^{2}$ & Adjusted $R^{2}$ & $\beta$ & SE & $P$ & $R^{2}$ & Adjusted $R^{2}$ \\
\hline Fat mass $(\mathrm{kg})$ & 0.59 & 0.03 & $<0.001$ & 0.30 & 0.30 & 0.46 & $0 \cdot 16$ & $<0.001$ & 0.31 & 0.31 \\
\hline Age ( $<60$ years) & 3.75 & 0.32 & $<0.001$ & & & $2 \cdot 20$ & 0.19 & $<0.001$ & & \\
\hline Regular physical activity (yes) & 1.07 & 0.30 & $<0.001$ & & & 0.89 & 0.20 & $<0.001$ & & \\
\hline Income ( $\geq 3000000 \mathrm{KRW})$ & 0.83 & 0.27 & 0.002 & & & * & & & & \\
\hline Smoking (yes) & 0.72 & 0.23 & 0.002 & & & * & & & & \\
\hline Alcohol consumption (yes) & * & & & & & 0.63 & $0 \cdot 17$ & $<0.001$ & & \\
\hline Protein intake $\ddagger$ (tertile 3 ) & 0.50 & 0.24 & 0.039 & & & * & & & & \\
\hline Chronic disease (yes) & $-2 \cdot 25$ & 0.96 & 0.019 & & & * & & & & \\
\hline
\end{tabular}

KRW, Korean won.

* The variable was not selected during the stepwise procedure due to $P>0.05$.

† Predictors were selected by a regression model with stepwise procedure.

$\ddagger$ Protein intake per $1000 \mathrm{kcal}(4184 \mathrm{~kJ})$. Variables initially included in the model were fat mass (kg), age (<60/ $\geq 60$ years), protein intake (T2, T3), marital status (married/others), education ( $\geq$ college/others), income ( $\geq 3000000 \mathrm{KRW}$ per month/others), smoking (yes/no), alcohol consumption (yes/no), regular physical activity (yes/no), self-perceived dental health status (poor/others), chronic diseases (myocardial infarction, congestive heart failure, coronary artery disease, peripheral arterial disease, cerebrovascular disease, asthma, chronic obstructive pulmonary disease, cancer, dementia and arthritis).

Table 3. Estimates of lean mass after a 12-year follow-up by protein intake according to obesity status at baselineł

\begin{tabular}{|c|c|c|c|c|c|c|c|c|}
\hline \multirow[b]{3}{*}{ Variables } & \multicolumn{4}{|c|}{ Men } & \multicolumn{4}{|c|}{ Women } \\
\hline & \multicolumn{2}{|c|}{ Total $(n$ 2096) } & \multirow{2}{*}{$\begin{array}{l}\text { Normal§ } \\
(n \text { 1574) }\end{array}$} & \multirow{2}{*}{$\begin{array}{l}\text { Obese } \| \\
(n \text { 522) }\end{array}$} & \multicolumn{2}{|c|}{ Total $(n$ 2316) } & \multirow{2}{*}{$\begin{array}{l}\text { Normal } \\
(n \text { 809) }\end{array}$} & \multirow{2}{*}{$\begin{array}{c}\text { Obese } \\
(n \text { 1507) }\end{array}$} \\
\hline & Model 1 & Model 2 & & & Model 1 & Model 2 & & \\
\hline Intercept & $45 \cdot 12$ & $37 \cdot 76$ & $44 \cdot 18$ & 48.04 & 36.82 & 28.95 & 35.28 & $37 \cdot 80$ \\
\hline \multicolumn{9}{|l|}{ Protein intake at baseline } \\
\hline Tertile 1 & Reference & Reference & Reference & Reference & Reference & Reference & Reference & Reference \\
\hline Tertile 2 & $-0.01 \neq \ddagger$ & -0.14 & 0.13 & -0.65 & $0.28 \dagger$ & 0.18 & $0.71^{* *}$ & -0.04 \\
\hline Tertile 3 & $0.79^{\star \star}$ & $0.35 \dagger$ & $0.85^{\star \star}$ & 0.45 & $0.28 \dagger$ & $0.28^{*}$ & $0.97^{\star \star}$ & -0.15 \\
\hline Age ( $<60$ years) & $5 \cdot 00^{\star *}$ & $4 \cdot 59^{* *}$ & $5 \cdot 29^{* *}$ & $4 \cdot 08^{\star *}$ & $2 \cdot 74^{\star *}$ & $2 \cdot 83^{\star *}$ & $3 \cdot 26^{\star *}$ & $2 \cdot 61^{\star \star}$ \\
\hline Income ( $\geq 3000000 \mathrm{KRW})$ & $1.46^{* *}$ & $0.91^{* *}$ & $1.49^{* *}$ & $1.36^{* *}$ & 0.25 & $0.32^{*}$ & -0.07 & $0.43^{*}$ \\
\hline Alcohol consumption (yes) & $0.55^{\star \star}$ & $0.36 \dagger$ & 0.33 & $1 \cdot 16^{\star \star}$ & $0.50^{\star \star}$ & $0.54^{\star *}$ & 0.31 & $0.56^{\star \star}$ \\
\hline Smoking (yes) & 0.20 & $0.73^{* *}$ & 0.23 & $1.82^{* *}$ & -0.15 & 0.04 & -0.20 & 0.21 \\
\hline Regular physical activity (yes) & $1.44^{\star \star}$ & $1.06^{\star *}$ & $1.63^{\star \star}$ & $0.88 \dagger$ & $1.22^{\star \star}$ & $0.93^{\star \star}$ & $2.08^{\star \star}$ & $0 \cdot 76^{\star \star}$ \\
\hline Chronic diseases (yes) & $-2.54^{\star *}$ & $-2 \cdot 52^{\star *}$ & $-2 \cdot 72^{\star \star}$ & $-2 \cdot 42 \dagger$ & -0.01 & 0.14 & -0.04 & 0.01 \\
\hline Fat mass $(\mathrm{kg})$ & & $0.56^{* *}$ & - & - & & $0.43^{* *}$ & - & - \\
\hline \multicolumn{9}{|l|}{ Goodness-of-fit } \\
\hline 2-Log likelihood & 26374.26 & 25537.57 & $19908 \cdot 14$ & 6415.08 & 25576.44 & 24465.73 & 8881.13 & 16634.66 \\
\hline
\end{tabular}

${ }^{*} P<0.05,{ }^{* *} P<0.01,+P<0.1$.

$\ddagger$ Model 1 was adjusted for age, income, alcohol consumption, smoking, regular physical activity and chronic diseases. Model 2 was adjusted for variables in model 1 plus fat mass. $\S$ Percentage body fat $<25$ for men and $<30$ for women.

|| Percentage body fat $\geq 25$ for men and $\geq 30$ for women.

I Protein intake per $1000 \mathrm{kcal}(4184 \mathrm{~kJ})$.

㧊 Coefficient estimates and standard errors are derived from linear mixed-effects models adjusted for lean mass at baseline.

Similar to the results reported by previous studies, regular physical activity was positively associated with lean mass retention in both men and women, regardless of obesity status. Recent meta-analyses have reported that exercise interventions may be beneficial in improving muscle strength and physical performance ${ }^{(56,59,60)}$. A prospective cohort study concluded that a higher intake of animal protein foods alone, especially in combination with a physically active lifestyle, was associated with the preservation of muscle mass and functional performance in elderly individuals ${ }^{(61)}$. A randomised controlled trial in elderly Japanese women with sarcopenia demonstrated significant effects of exercise and amino acid supplementation on the enhancement of muscle strength and on the combined variables of muscle mass and walking speed or muscle mass and strength $^{(62)}$. The lifestyles of obese men and women may, therefore, have an important influence on the retention of lean mass.
The strengths of the present study include its large cohort and long follow-up period, which enabled the investigation of associations between protein intake from habitual diets and lean mass in Korean elderly. However, our study also had several limitations. BIA for assessing muscle mass is a useful non-invasive method in large population-based studies; however, factors such as age, hydration status, food or beverage consumption and exercise intensity may affect the results. To reduce the possibility of measurement errors, the participants were requested to fast before BIA assessment, and their hydration status was monitored carefully. The European Working Group on Sarcopenia in Older People suggested BIA as a portable alternative to dual-energy X-ray absorptiometry ${ }^{(6)}$. Additionally, we assessed dietary protein intake only at baseline and did not determine whether the protein intake of participants had changed over the course of the followup period. 


\section{Conclusions}

Our findings support the current evidence that higher protein intakes are beneficial in preserving lean mass. The associations between dietary protein and increased lean mass were more apparent in the normal-weight group but were not detected in the obese group. Our population-based findings may inform the development of improved healthcare programmes for the Korean elderly, with an aim to preserve muscle mass and maintain functionality. However, further comprehensive investigations of the factors affecting muscle strength, functional status and muscle mass are needed to clarify the dose-response effects of varying weight status in older adults.

\section{Acknowledgements}

This research received no specific grant from any funding agency, commercial or not-for-profit sectors.

E. S. performed data analyses and wrote the paper; H. J. and S. K. C. reviewed the manuscript. All authors take primary responsibility for the final content.

The authors have no conflicts of interest associated with the present study.

\section{References}

1. Beard J, Officer A \& Cassels A (2016) World Report on Ageing and Health. Geneva: World Health Organization.

2. Chen LK, Lee WJ, Peng LN, et al. (2016) Recent advances in Sarcopenia Research in Asia: 2016 update from the Asian Working Group for Sarcopenia. J Am Med Dir Assoc 17, e761-e767.

3. Fielding RA, Vellas B, Evans WJ, et al. (2011) Sarcopenia: an undiagnosed condition in older adults. Current consensus definition: prevalence, etiology, and consequences. International working group on sarcopenia. J Am Med Dir Assoc 12, 249-256.

4. Beaudart C, Rizzoli R, Bruyère $O$, et al. (2014) Sarcopenia: burden and challenges for public health. Arch Public Health 72, 45 .

5. Sousa A, Guerra R, Fonseca I, et al. (2016) Financial impact of sarcopenia on hospitalization costs. Eur J Clin Nutr 70, 1046.

6. Cruz-Jentoft AJ, Baeyens JP, Bauer JM, et al. (2010) Sarcopenia: European consensus on definition and diagnosis: report of the European Working Group on Sarcopenia in older people. Age Ageing 39, 412-423.

7. Rom O, Kaisari S, Aizenbud D, et al. (2012) Lifestyle and sarcopenia - etiology, prevention, and treatment. Rambam Maimonides Med J 3, e0024.

8. Isanejad M, Mursu J, Sirola J, et al. (2015) Association of protein intake with the change of lean mass among elderly women: the Osteoporosis Risk Factor and Prevention - Fracture Prevention Study (OSTPRE-FPS). J Nutr Sci $\mathbf{4}$, e41.

9. Volpi E, Campbell WW, Dwyer JT, et al. (2012) Is the optimal level of protein intake for older adults greater than the recommended dietary allowance? J Gerontol A Biol Sci Med Sci 68 , 677-681.

10. Fulgoni III VL (2008) Current protein intake in America: analysis of the National Health and Nutrition Examination Survey, 2003-2004. Am J Clin Nutr 87, 1554S-1557S.

11. Fakhouri TH, Ogden CL, Carroll MD, et al. (2012) Prevalence of Obesity among Older Adults in the United States, 2007-2010. NCHS data brief, no. 106. Hyattsville, MD: National Center for Health Statistics.
12. Choi KM (2016) Sarcopenia and sarcopenic obesity. Korean J Intern Med 31, 1054-1060.

13. Goisser S, Kemmler W, Porzel S, et al. (2015) Sarcopenic obesity and complex interventions with nutrition and exercise in community-dwelling older persons - a narrative review. Clin Interv Aging 10, 1267-1282.

14. Stenholm S, Alley D, Bandinelli S, et al. (2009) The effect of obesity combined with low muscle strength on decline in mobility in older persons: results from the InCHIANTI study. Int J Obesity 33, 635.

15. Lee S, Kim TN \& Kim SH (2012) Sarcopenic obesity is more closely associated with knee osteoarthritis than is nonsarcopenic obesity: a cross-sectional study. Arthritis Rheum 64, 3947-3954.

16. Rantanen T, Harris T, Leveille SG, et al. (2000) Muscle strength and body mass index as long-term predictors of mortality in initially healthy men. J Gerontol A Bio Sci Med Sci 55, M168-M173.

17. Fujioka S, Matsuzawa Y, Tokunaga K, et al. (1987) Contribution of intra-abdominal fat accumulation to the impairment of glucose and lipid metabolism in human obesity. Metab Clin Exp 36, 54-59.

18. Nilsson MI, Dobson JP, Greene NP, et al. (2013) Abnormal protein turnover and anabolic resistance to exercise in sarcopenic obesity. FASEB J 27, 3905-3916.

19. Kewalramani G, Bilan PJ, Klip A, et al. (2010) Muscle insulin resistance: assault by lipids, cytokines and local macrophages. Curr Opin Clin Nutr Metab Care 13, 382-390.

20. Hayden MS \& Ghosh SJ (2012) NF- $\kappa B$, the first quarter-century: remarkable progress and outstanding questions. Genes Dev $\mathbf{2 6}$, 203-234.

21. Johnson MA, Polgar J, Weightman D, et al. (1973) Data on the distribution of fibre types in thirty-six human muscles: an autopsy study. J Neurol Sci 18, 111-129.

22. Erskine RM, Tomlinson DJ, Morse CI, et al. (2017) The individual and combined effects of obesity-and ageing-induced systemic inflammation on human skeletal muscle properties. Int J Obes (Lond) 41, 102.

23. Statistics Korea (2017) Statistics on the Aged. http://kostat.go. $\mathrm{kr} /$ portal/eng/pressReleases/11/3/index.board?bmode=read \&bSeq $=\& a S e q=363974$ \&page $\mathrm{No}=1 \&$ row Num $=10 \&$ navCount $=$ $10 \&$ currPg=\&sTarget=title\&sTxt= (accessed September 2018).

24. Kim Y, Han BG \& Ko GESg (2017) Cohort profile: the Korean Genome and Epidemiology Study (KoGES) consortium. Int J Epidemiol 46, e20.

25. Kim TN, Yang SJ, Yoo HJ, et al. (2009) Prevalence of sarcopenia and sarcopenic obesity in Korean adults: the Korean Sarcopenic Obesity Study. Int J Obes (Lond) 33, 885-892.

26. Ahn Y, Kwon E, Shim JE, et al. (2007) Validation and reproducibility of food frequency questionnaire for Korean Genome Epidemiologic Study. Eur J Clin Nutr 61, 1435-1441.

27. Cho YG, Song HJ, Kim JM, et al. (2009) The estimation of cardiovascular risk factors by body mass index and body fat percentage in Korean male adults. Metabolism 58, 765-771.

28. Kim JY, Han SH \& Yang BM (2013) Implication of high-body-fat percentage on cardiometabolic risk in middle-aged, healthy, normal-weight adults. Obesity 21, 1571-1577.

29. Nelson ME, Rejeski WJ, Blair SN, et al. (2007) Physical activity and public health in older adults: recommendation from the American College of Sports Medicine and the American Heart Association. Circulation 116, 1094.

30. World Health Organization (2010) Physical activity and older adults: Recommended levels of physical activity for adults aged 65 and above. http://www.who.int/dietphysicalactivity/ factsheet_recommendations/en/ (accessed September 2018).

31. Goodpaster BH, Park SW, Harris TB, et al. (2006) The loss of skeletal muscle strength, mass, and quality in older adults: 
the health, aging and body composition study. J Gerontol A Biol Sci Med Sci 61, 1059-1064.

32. Willett WC, Howe GR \& Kushi LH (1997) Adjustment for total energy intake in epidemiologic studies. Am J Clin Nutr $\mathbf{6 5}$, 1220S-1228S

33. Kim JE, O'Connor LE, Sands LP, et al. (2016) Effects of dietary protein intake on body composition changes after weight loss in older adults: a systematic review and meta-analysis. Nutr Rev 74, 210-224.

34. Houston DK, Nicklas BJ, Ding J, et al. (2008) Dietary protein intake is associated with lean mass change in older, community-dwelling adults: the Health, Aging, and Body Composition (Health ABC) study. Am J Clin Nutr 87, 150-155.

35. Farsijani S, Payette H, Morais JA, et al. (2017) Even mealtime distribution of protein intake is associated with greater muscle strength, but not with 3-y physical function decline, in freeliving older adults: the Quebec longitudinal study on Nutrition as a Determinant of Successful Aging (NuAge study). Am J Clin Nutr 106, 113-124.

36. Robinson SM, Jameson KA, Batelaan SF, et al. (2008) Diet and its relationship with grip strength in community-dwelling older men and women: the Hertfordshire Cohort Study. J Am Geriatr Soc 56, 84-90.

37. Martin H, Aihie Sayer A, Jameson K, et al. (2011) Does diet influence physical performance in community-dwelling older people? Findings from the Hertfordshire Cohort Study. Age Ageing 40, 181-186.

38. Farsijani S, Morais JA, Payette H, et al. (2016) Relation between mealtime distribution of protein intake and lean mass loss in free-living older adults of the NuAge study. Am J Clin Nutr 104, 694-703.

39. Isanejad M, Mursu J, Sirola J, et al. (2016) Dietary protein intake is associated with better physical function and muscle strength among elderly women. Br J Nutr 115, 1281-1291.

40. Meng X, Zhu K, Devine A, et al. (2009) A 5-year cohort study of the effects of high protein intake on lean mass and BMC in elderly postmenopausal women. J Bone Miner Res 24, 1827-1834.

41. Chan R, Leung J, Woo J, et al. (2014) Associations of dietary protein intake on subsequent decline in muscle mass and physical functions over four years in ambulant older Chinese people. J Nutr Health Aging 18, 171-177.

42. Yamaguchi M, Yamada Y, Nanri H, et al. (2018) Association between the frequency of protein-rich food intakes and Kihon-Checklist frailty indices in older Japanese adults: the Kyoto-Kameoka study. Nutrients 10.

43. Morley JE, Argiles JM, Evans WJ, et al. (2010) Nutritional recommendations for the management of sarcopenia. J Am Med Dir Assoc 11, 391-396.

44. Wolfe RR, Miller SL \& Miller KB (2008) Optimal protein intake in the elderly. ClinNutr 27, 675-684.

45. Bauer J, Biolo G, Cederholm T, et al. (2013) Evidence-based recommendations for optimal dietary protein intake in older people: a position paper from the PROT-AGE Study Group. J Am Med Dir Assoc 14, 542-559.
46. Landi F, Calvani R, Tosato M, et al. (2016) Protein intake and muscle health in old age: from biological plausibility to clinical evidence. Nutrients $\mathbf{8}$.

47. Korea Centers for Disease Control and Prevention (2016) Koreal Health Statistics 2015. Sejong, Korea: Ministry of Health and Welfare.

48. Newman AB, Kupelian V, Visser M, et al. (2003) Sarcopenia: alternative definitions and associations with lower extremity function. J Am Geriatr Soc 51, 1602-1609.

49. Baumgartner RN (2000) Body composition in healthy aging. Ann NYAcad 904, 437-448

50. Stephen W \& Janssen I (2009) Sarcopenic-obesity and cardiovascular disease risk in the elderly. J NutrHealth Aging 13, $460-466$.

51. Tian S \& Xu Y (2016) Association of sarcopenic obesity with the risk of all-cause mortality: a meta-analysis of prospective cohort studies. Geriatr Gerontol Int 16, 155-166.

52. Li R, Xia J, Zhang X, et al. (2017) Associations of muscle mass and strength with all-cause mortality among US older adults. Med Sci Sports Exerc 50, 458-467.

53. Brady AO, Straight C, Schmidt M, et al. (2014) Impact of body mass index on the relationship between muscle quality and physical function in older women. J Nutr Health Aging 18, 378-382.

54. Himes CL \& Reynolds SL (2012) Effect of obesity on falls, injury, and disability. J Am Geriatr Soc 60, 124-129.

55. Koster A, Patel KV, Visser M, et al. (2008) Joint effects of adiposity and physical activity on incident mobility limitation in older adults. J Am Geriatr Soc 56, 636-643.

56. Liao C-D, Tsauo J-Y, Wu Y-T, et al. (2017) Effects of protein supplementation combined with resistance exercise on body composition and physical function in older adults: a systematic review and meta-analysis. Am J Clin Nutr 106, 1078-1091.

57. Bowen TS, Schuler G \& Adams V (2015) Skeletal muscle wasting in cachexia and sarcopenia: molecular pathophysiology and impact of exercise training. J Cachexia Sarcopenia Muscle 6, 197-207.

58. Potes Y, de Luxan-Delgado B, Rodriguez-Gonzalez S, et al. (2017) Overweight in elderly people induces impaired autophagy in skeletal muscle. Free Radic Biol Med 110, 31-41.

59. Cruz-Jentoft AJ, Landi F, Schneider SM, et al. (2014) Prevalence of and interventions for sarcopenia in ageing adults: a systematic review. Report of the International Sarcopenia Initiative (EWGSOP and IWGS). Age Ageing 43, 748-759.

60. Beaudart C, Dawson A, Shaw SC, et al. (2017) Nutrition and physical activity in the prevention and treatment of sarcopenia: systematic review. Osteoporos Int 28, 1817-1833.

61. Bradlee ML, Mustafa J, Singer MR, et al. (2017) High-protein foods and physical activity protect against age-related muscle loss and functional decline. J Gerontol A Bio Sci Med Sci $\mathbf{7 3}$, 88-94.

62. Kim HK, Suzuki T, Saito K, et al. (2012) Effects of exercise and amino acid supplementation on body composition and physical function in community-dwelling elderly Japanese sarcopenic women: a randomized controlled trial. $J \mathrm{Am}$ Geriatr Soc 60, 16-23. 